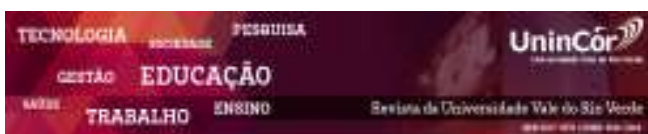

Revista da Universidade Vale do Rio Verde ISSN: 1517-0276 / EISSN: 2236-5362 v. 17 | n. 1 | Ano 2019

Fernanda Cristina Beraldo Rezende Faculdades Unidas do Norte de Minas- FUNORTE fe.cris.enfermagem@gmail.com

Hilária Kênia Santos Lisboa Faculdades Unidas do Norte de Minas- FUNORTE hilarialisboa@hotmail.com

Lyllian Aparecida Vieira Almeida

Faculdades Unidas do Norte de Minas- FUNORTE lyllianvieira@hotmail.com

Emerson Ribeiro Lima

Universidade Estadual de Montes Claros - UNIMONTES emrlima86@gmail.com

Meriele Santos Souza

Faculdades Unidas do Norte de Minas- FUNORTE. meriele.souza@funorte.edu.br

Romana Aparecida Alves Barbosa Universidade Estadual de Montes Claros - UNIMONTES romanabarbosa@yahoo.com.br

Karla Chistiane Freitas Oliveira Universidade Estadual de Montes Claros - UNIMONTES kcfoliveira@yahoo.com.br

Mariza Alves Barbosa Teles Faculdades Unidas do Norte de Minas- FUNORTE aziramteles@gmail.com

\section{A SEXUALIDADE DA MULHER NO CLIMATÉRIO}

\section{RESUMO}

O climatério é o processo de transição entre as fases biológica e não patológica caracterizado pelo período reprodutivo e o não reprodutivo. $\mathrm{O}$ objetivodesde estudo foi descrever o conhecimento das mulheres sobre o climatério e as consequências dessa fase em sua sexualidade. Trata-se de um estudo qualitativo e descritivo realizado com oito mulheres cadastradas em Unidade Básica de saúde, no período de agosto a setembro de 2011, em Juramento(MG), Brasil. Para a produção dos dados foi empregada aentrevista semiestruturada, e análise de conteúdo na modalidade temática foi a técnica utilizada para a análise dos dados. Os dados encontrados mostraram quea maioria das participantes desconhece o que é climatério. As falas das mulheres deixam transparecer o significativo do medo de perda da jovialidade e da beleza, além da diminuição do desejo e, consequentemente, da redução da frequência da atividade sexual. Conclui-se que poucas mulheres estão informadas e buscam novos conhecimentos e se preparam para a chegada dessa fase. Espera-se que este estudo traga contribuições para nortear o trabalho dos profissionais de enfermagem nas organizações de atendimento voltadas a este público.

Palavras-chave:Sexualidade. Climatério. Saúde da mulher. Conhecimento. Influência.

\section{THE SEXUALITY OF WOMEN IN THE CLIMATE}


knowledge and prepare for the arrival of this phase. It is hoped that this study will bring contributions to guide the work of nursing professionals in the care organizations focused on this public.

KEYWORDS: Sexuality. Climacteric. Women's Health. Knowledge. Influence.

Recebido em: 08/03/2018 - Aprovado em: 19/03/2019 - Disponibilizado em: 15/07/2019

\section{INTRODUÇÃO}

O climatério consiste em uma fase do ciclo feminino que tem início normalmente por volta dos 40 anos de idade, podendo se estender até os 65. É o processo de transição entre as fases biológica e não patológica caracterizado pelo período reprodutivo e o não reprodutivo. Abrange a fase em que os hormônios estrogênio e progesterona vão deixando de serem produzidos, levando a maioria das mulheres a vivenciarem sinais e sintomas que trazem desconforto em maior ou menor grau, com mudanças drásticas em seus hábitos diários, podendo comprometer sua vida e acarretar alterações, envolvendo o contexto psicossocial.A menopausa é um marco nessa fase, correspondendo ao último fluxo menstrual, comprovado por meio da amenorréia espontânea por 12 meses consecutivos(BRASIL, 2008).

As mudanças ocorridas no climatério incluem uma série de implicações sociais e culturais relacionadas ao envelhecimento e a sexualidade, marcadas por momentos de intensa euforia, medos e dificuldade social, em virtude dos vários sintomas apresentados. Dentre os diversos estudos relacionados ao climatério, destacam- se as transformações relacionadas à queda brusca ou ao desequilíbrio hormonal, ao estado geral da mulher, ao estilo de vida adotado, às relações sociais e aos projetos de vida que podem resultar em disfunções sexuais como diminuição da libido, vaginismo, dispareunia e decréscimo na lubrificação vaginal que, por sua vez, afetam o desempenho sexual e a sexualidade(SILVA; BORGES, 2012).

Dessa forma, nota- se que sexualidade não é sinônimo de sexo, pois não se resume apenas ao intercurso sexual. Sua manifestação ocorre de diversas formas através da afinidade entre pessoas, seja pelo contato físico, carinho, zelo, sensualidade, entre outras formas, que não apenas $\mathrm{o}$ ato sexual propriamente dito. $\mathrm{O}$ ato sexual diferencia-se em diversos aspectos de acordo com cada cultura. Sendo assim, a maneira como é vivenciado ou mesmo os valores atribuídos, dependerá da construção cultural de cada indivíduo(SANTOS et al, 2014).

Nos tempos atuais, as mulheres têm se preocupado mais com as mudanças que ocorrem com o seu corpo, inclusive têm dissociado o sexo como meramente por questões reprodutivas, levando em consideração também o seu aspecto 
prazeroso, a fim de obter uma melhoria em sua vida, o que significa também ficar livre dos sintomas do climatério que prejudicam seu bemestar físico e mental, tornando evidente a necessidade de atenção nesta área(PASCOAL; BORGES, 2013).

$\mathrm{Na}$ assistência à mulher que está vivenciando o climatério, sabe-se que se deve atender à mesma de maneira integral e individualizada. Porém, na prática, essas ações ainda não são desenvolvidas.Apesar do grande número de mulheres na fase da menopausa apontadas pelas estatísticas a cada ano, ainda há escassez de estudos nesta área o que remete à importância de enfocar melhor as questões relacionadas ao climatério(ALVES et al, 2015).

Assim, espera-se que este estudo possa fornecer contribuições aos profissionais que atuam diretamente nesta área, estabelecendo um elo de confiança com estas mulheres, para que se desenvolva uma comunicação adequada de modo que venha a compreender melhor as mudanças que ocorrem neste período de transição e que a mesma seja capaz de vivenciar essa fase livre de mitos e preconceitos.

Neste sentido, a investigação teve como objetivo descrever o conhecimento das mulheres sobre o climatério e as consequências dessa fase em sua sexualidade.

\section{MÉTOdOS}

Estudo exploratório, descritivo, de abordagem qualitativa, desenvolvido no período de agosto a setembro de 2011, na cidade de Juramento(MG), Brasil.
Foram selecionadas como participantes da presente pesquisa oito mulheres, usuárias de uma Unidade Básica de Saúde (UBS) da cidade de Juramento (MG), Brasil, indicadas pelos Agentes Comunitário de Saúde (ACS). Foram utilizados como critérios de inclusão: ser mulher na faixa etária entre 40 a 50 anos; está cadastrada na UBS selecionada no momento da coleta de dados e ter condições cognitivas e emocionais de responder à entrevista. Foram excluídas as mulheres que não atenderam a esses critérios.

A produção dos dados foi realizada por meio de entrevista semiestruturada, gravada e transcrita na íntegra e, posteriormente, analisada. A entrevista baseou-se em um roteiro contendo as seguintes questões norteadoras: Qual seu conhecimento sobre o climatério? Qual a influência do climatério na sua sexualidade? O que a assistência à saúde tem ajudado nesta fase da vida? Da análise dessas questões e de outras surgidas no momento da entrevista, emergiu a necessidade de questionamentos mais específicos, possibilitando o aprofundamento e aprimoramento do assunto tratado.

As entrevistas foram realizadas individualmente pelos próprios pesquisadores e teve duração aproximada de 30 minutos. O término da coleta de dados foi por saturação teórica dos dados, em que ocorre a interrupção da coleta de dados quando se constata que elementos novos para subsidiar a teorização almejada não são mais depreendidos a partir do campo de observação(PIRES, 2008; FONTANELLA et al, 2011).

Para fins de discussão, recorreu-se à técnica de análise de conteúdo, na modalidade temática, entendida como um método que 
abrange um conjunto de técnicas de análise dos diálogos, utilizando procedimentos de descrição do conteúdo das mensagens coletadas(BARDIN, 2009). Foi realizada uma pré-análise do material, visando a sua organização de acordo com o objetivo da pesquisa e, em seguida procedeu-se à exploração desse material, seguida da interpretação e dedução, de acordo com o quadro teórico do estudo(BARDIN, 2009). A partir desse processo surgiram três categorias temáticas: Conhecimentos sobre o climatério; A influência do climatério na sexualidade e Assistência à saúde no climatério. Estes resultados foram confrontados e discutidos com base na literatura pertinente, gerando então as considerações sobre o trabalho.

Estabeleceu-se o cuidado de proporcionar às mulheres a liberdade e a espontaneidade necessárias para relatarem seus conhecimentos experiências de maneira ampla e equilibrada para que pudessem descrever de forma mais precisa essa nova fase em suas vidas. Para manter o anonimato das participantes, seus nomes foram codificados por M1, M2, e assim por diante, assegurando-lhes assim o sigilo de suas identidades.

Este estudo obedeceu às normas regulamentadoras da Resolução No 466, de 12 de dezembro de 2012 do Conselho Nacional de Saúde (CNS) sobre Diretrizes e Normas Regulamentadoras de Pesquisa Envolvendo Seres Humanos, sendo o projeto de pesquisa enviado ao Comitê de Ética em Pesquisa (CEP) da SOEBRAS e obteve parecer consubstanciado de nº1686/11. Após a explicação do objetivo do estudo a todas as participantes, foi solicitada sua anuência para a participação no mesmo, por meio de sua assinatura no Termo de Consentimento Livre e Esclarecido (TCLE).

\section{RESULTADOS E DISCUSSÃO}

A população desta pesquisa constituiu-se de oito mulheres, com faixa etária entre 41 a 50 anos, Destas, sete(07) eram casadas e/ou vivem com companheiro e uma(01) viúva e não se encontrava em nenhum relacionamento amoroso no momento. Vale ressaltar que a maioria das participantes possuíam apenas o ensino fundamental e uma (01) curso superior. A maioria exercia atividade remunerada e apenas uma(01) participante declarou ser "do lar". Todas as participantes tinham filhos e cinco (05) delas se encontravam na menopausa.

\section{Conhecimentos sobre o climatério}

É importante considerar que o climatério não é apenas a transição do período reprodutivo para o não reprodutivo, mas se caracteriza como um conjunto de manifestações biopsicossociais e hormonais. Para a mulher, é um período de difícil adaptação, acompanhado de sofrimento físico e emocional, em que há umavariedade de mulheres mal informadas e predispostas à rejeição de si próprias à medida, que começam a envelhecer. Nesse período, a mulher passa a vivenciar alterações nos aspectos social e corporal, o que pode ocasionar problemas na sua vida(ROCHA et $a l, 2014)$.

Verificou-se que a maioria das participantes desconhece o verdadeiro significado do termo climatério, e o mesmo foi relacionado e 
confundido com menopausa ou "passagem de idade", conforme evidenciado pelas participantes a seguir:

“Eu já vi falar que é a mesma coisa de menopausa." (M-5)

"Eu acho que o climatério é a chegada da mulher aos 45 anos." (M-6)

"Acho que climatério é a idade em que a mulher chega e ela vai parar de menstruar." (M-3)

Estudo realizado aponta que a maior parte das mulheres tem uma visão inconsistente e superficial acerca do assunto, com grandes dificuldades de discernir acerca do sentido de menopausa e climatério, além da visão do climatério como: terceira idade, doença, mudança hormonal e fase da vida. Para a maioria, a menopausa vem a ser a cessação do mênstruo e o fim da fertilidade(VALENÇA; GERMANO, 2010).

No discurso das entrevistadas é possível notar que as mulheres desconhecem o termo climatério, na maioria das vezes associando-o à menopausa. Muitas se negaram a responder, justamente pelo fato de não conhecerem o tema. Diante desta realidade é evidente a necessidade do desenvolvimento de ações de caráter educativo com o objetivo de favorecer conhecimentos acerca do assunto para que possam vivenciar com dignidade esta fase.

Quando questionadas sobre a percepção de mudanças no seu corpo, nos sentimentos ou nas relações sociais durante a fase do climatério, apenas duas participantes descrevem com clareza de detalhes os sintomas vividos no climatério, sendo as ondas de calor o principal a ser observado e relatado pela maioria das mulheres, como se segue nas falas:

"Agente sente que engorda mais, sentimento nem se fala, me deu depressão, fiquei com a pele mais seca, lá (vagina), então nem se fala, olha no espelho tá horrível né?! Sinto muito calor. Nossa! Eu fiquei ruim." (M-7)

Esses depoimentos corroboram com uma pesquisa, cujo resultado mostrou que as mulheres quando completam os 40 anos começam a perceber algumas mudanças fisiológicas no seu organismo, surgem alguns transtornos no seu dia a dia que são características do climatério, causando desconforto e incômodo. Alguns dos sinais e sintomas do climatério são os fogachos, a sudorese, irritabilidade, cefaléia, atrofia genital e insônia(PASCOAL; BORGES, 2013; VALENÇA; GERMANO, 2010).

Durante o climatério as manifestações neuropsíquicas muitas vezes são as primeiras a surgirem (distúrbios vasomotores, ansiedade, depressão, fadiga). As alterações hormonais podem trazer algum desconforto e insegurança para as mulheres e ao mesmo tempo diminuir sua capacidade produtiva, expressando confusões emocionais no cotidiano familiar, social e até mesmo pessoal(BRASIL, 2008).

\section{Influência do climatério na sexualidade}

Ao serem abordadas sobre a interferência da sexualidade na fase do climatério, foi notória a negação da percepção das entrevistadas sobre tais modificações, conforme evidenciado abaixo:

“Ainda não percebi nada.” (M-2 e M-8) 
Observou-se que as participantes demonstraram constrangimento, timidez e insatisfação, representados por alterações no tom de voz. Além das manifestações de insatisfação sobre o assunto, as declarações sempre vieram acompanhadas de expressões negativas que demonstram muito bem que se tratava de alguma coisa sobre a qual não se deviam falar.

$\mathrm{O}$ que se pode observar no presente estudo foramàs mudanças sexuais comumente apresentadas pelas participantes como a perda da libido e o ressecamento vaginal seguido da dispareunia. A vivência da sexualidade para algumas entrevistadas foi relatada como fonte de sofrimento sob diferentes aspectos:

“Tive sim. Ah!... a gente perde a vontade, sente dor... um tanto de coisa.” (M-6)

“Eu não sei se é isso, mais de uns tempos pra cá, eu tô muito fria com meu marido. Quando vou ter relação com ele eu sinto muita dor, parece que tá ressecado, né?!” (M-1)

Nessas narrativas, é possível constatar que o desinteresse sexual apresentado pela mulher tem na diminuição da libido sua principal justificativa. As alterações como depressão, irritabilidade, insegurança e insatisfação também estiveram presentes.

As disfunções sexuais femininas incluem interesse e motivação sexuais prejudicados, dificuldades em se sentir excitada e dificuldades para desencadear o desejo durante o envolvimento sexual. Mudanças no epitélio e na musculatura vaginal decorrentes das alterações hormonais, acrescidas da diminuição na lubrificação genital provocam secura vaginal e, muitas vezes, dispaurenia, condições que têm sido responsabilizadas pelo comprometimento da atividade sexual feminina nesse período(SANTOS et al, 2014; MELO et al, 2016).

Quando indagadas se o climatério teve interferência na sua sexualidade, algumas mulheres revelaram-se constrangidas em expressarem suas respostas, o que as levou a negar as influências dessa fase em sua sexualidade:

"Não, continua a mesma coisa." (M-3, M-4 e M5).

As descobertas deste resultado são contrárias às de uma pesquisa sobre a percepção de mulheres usuárias da estratégia saúde da família em relação aoclimatério e menopausa ao encontrar que algumas mulheres não referem problemas de ordem sexual na fase do climatério e sentem-se, inclusive, mais maduras e livres para a vivência da sua sexualidade. A explicação para tal afirmação baseia-se fundamentalmente, na maneira que vivenciam a sexualidade no decorrer de toda a vida, bem como nas relações positiva que estabelecem com seus parceiros(ARANHA et al, 2016).

\section{Assistência à saúde no climatério}

Convém ressaltar que quando se investiga a assistência à saúde da mulher no climatério, pouco tem sido feito, ficando na dependência de ações restritas e individualizadas. A falta de informações e de educação em saúde voltadas a este tema aumenta ainda mais as angústias e incertezas, fazendo com que as próprias mulheres 
se sintam seres negativos, alimentando a sensação de solidão, impulsionando assim o surgimento de questões que dificultam a vivência harmoniosa com o companheiro, principalmente relacionado ao exercício da sexualidade(ROCHA et al, 2014).

Alguns autores advertemsobre a procura de serviço de saúde por mulheres climatéricas brasileiras, ao afirmarem que a principal razão para a não-procura desses serviços é a concepção de que essa fase é natural, não merecendo atenção médica(FREITAS et al, 2016).

Percebe-se o fato de que a assistência à saúde da mulher refere-se apenas a realização do exame de Prevenção de Câncer de Colo Uterino(PCCU), pré-natal e planejamento familiar, não se levando em consideração as demais fases da vida, incluindo a do climatério. Verifica-se entre as participantes que apenas uma buscou o serviço de saúde nessa fase da vida, enquanto outras justificaram a não procura devido à vergonha em abordar este assunto.

“Não, tinha vergonha.” (M-4)

"Tenho vergonha de falar dessas coisas, mais qualquer hora eu vou lá.” (M-1)

A limitação das mulheres em exporem verbalmente suas respostas deveu-se à timidez, que representava um reflexo de uma vivência permeada por valores morais, religiosos $\mathrm{e}$ culturais muito rígidos, interferindo significativamente nas experiências em sua sexualidade(SANTOS et al, 2014).

Nota-se que a maioria das mulheres não procura o serviço de saúde para auxílio relacionado ao climatério, e somente quando estão doentes buscam esse serviço, refletindo uma deficiência no autocuidado e uma lacuna nas ações de promoção da saúde e de prevenção das doenças da mulher pelos serviços de saúde, especialmente na Atenção primária à Saúde.

“Não, eu não acho que tive necessidade ainda." $(M-5)$

"Não, por enquanto eu não procurei não, eu não tô sentindo muita coisa." (M-3)

Muitas mulheres influenciadas por crenças populares buscam alívio nos sintomas experimentados por elas na medicina natural, usando chás, garrafadas e etc. $O$ uso de medicamentos naturais à base de ervas acontece indiscriminadamente, sem qualquer acompanhamento. O que se pôde observar nas falas das mulheres entrevistadas é que elas reconhecem que deveriam procurar o serviço de saúde, mas só o fazem quando não encontram uma forma de alivio nas ervas, conforme elucidado por algumas das entrevistadas:

"Não procurei o serviço de saúde, mas tô tomando chá de folha de amora e quando eu tomo sinto a melhora logo, logo. Eu só procuro o serviço de saúde quando eu não toagüentando mais, mais o calor ainda dá pra agüentar...(risos). ” (M-2)

O número de mulheres que buscam as terapias complementares e alternativas para aliviar os sintomas do climatério tem crescido nos últimos tempos, sendo que, o ideal seria que todas buscassem orientação e educação em saúde acerca do assunto(SERPA et al, 2016).

Vale ressaltar um aspecto que chamou a atenção no estudo foi que as demais participantes 
relataram não buscarem assistência nos serviços de saúde alegando que os mesmos não oferecem a devida assistência, é o que demonstra as falas abaixo:

"Não procurei porque acho que a assistência nessa parte ainda é muito fraca, porque eu vejo que o pessoal da saúde não tem muito tempo pra isso não.” (M-8)

No contexto da insegurança das mulheres quanto à busca por ajuda no tratamento de seus sintomas, a situação revela que as mesmas não têm coragem de fazer perguntas aos profissionais de saúde pelo fato destes não possuírem conhecimento ou não estarem dispostos a esclarecerem e discutirem as dúvidas das mulheres durante a consulta, deixando-as passivas e confusas(SILVA; BROGES, 2012).

A sexualidade merece particular atenção no climatério, por ser reconhecida como um dos pilares da vida, porém a sua abordagem nem sempre é feita adequadamente no climatério por constrangimento das mulheres ou despreparo dos próprios profissionais de saúde em lidarem com essa questão(MIRANDA; FERREIRA; CORRENTE, 2014).

Diante dos problemas do climatério, o profissional deve refletir e buscar a percepção geral acerca das mudanças dessa fase, a fim de construir um trabalho participativo que propicie educação e suporte emocionala essas mulheres. É preciso compreender e trabalhar com enfoque numa assistência holística, considerando sua realidade social, econômica, cultural e emocional da mulher climatérica(SCHMALFUSSI et al, 2014).
Ressalta-se que apenas uma entrevistada estava atenta às mudanças que ocorreram em seu corpo e referiu ter buscado ajuda no serviço de saúde e estar fazendo o necessário para evitar as consequências deletérias em sua vida nesse período, por exemplo, através de acompanhamento médico periódico.

"Eu procurei o serviço de saúde, fui ao ginecologista, que me pediu exame de mama, papanicolau, e ultrassom intravaginal, fui também ao psiquiatra né....que me passou medicamentos antidepressivos e também no ortopedista, porque tem a falta de cálcio nos ossos, tomei cálcio durante 6 meses e vou repetir os exames para ver como esta." (M-7)

O consenso atual é que viver com qualidade seja o grande diferencial para enfrentar as mudanças ocorridas no climatério. A grande preocupação com esse aspecto, ao longo dos anos originou-se do reconhecimento pelos profissionais de saúde acerca da importância dos sentimentos e percepção dos indivíduos, bem como da monitorização do seu bem estar frente a medidas terapêuticas tomadas com vistas a prolongar a vida, aliviar a dor, restaurar funções ou prevenir incapacidades(ARANHA et al, 2016)

\section{CONSIDERAÇÕES FINAIS}

O climatério refere-se a uma fase natural da vida da mulher e representa o fim do ciclo reprodutivo, mas não da vida. Essa fase é acompanhada de manifestações clínicas que podem alterar o ritmo e a qualidade de vida destas 
mulheres, porém são passageiras, e se a mulher tiver um bom conhecimento acerca desse processo e de seu próprio corpo, essa parte pode passar quase que despercebida. Porém, são poucas as mulheres que estão informadas e buscam novos conhecimentos acerca desta temática.

Ficou evidente no estudo o desconhecimento das participantes quanto ao assunto climatério; o mesmo foi relacionado e confundido com

\section{REFERÊNCIAS}

ALVES, E. R. P.; COSTA, A. M.; BEZERRA, S. M. M. S.; NAKANO, M. A. S.; CAVALCANTI, A. M. T. S.; DIAS, M. D. Climatério: a intensidade dos sintomas e o desempenho Sexual. Texto Contexto Enferm, Florianópolis. Jan-Mar. 2015; 24(1): 64-71.

Disponível em:

<http://www.scielo.br/pdf/tce/v24n1/pt_0104-0707tce-24-01-00064.pdf>. Acesso em: 14 julho 2017.

ARANHA, J. S.; LIMA, C. B.; LIMA, M. N. F.A.; NOBRE, J. O .C. Climatério e menopausa: percepção de mulheres usuárias da estratégia saúde da família. Temas em Saúde. 2016[ acesso em 2017 Jan 23]; v. 16, n. 2. ISSN 2447-2131. João Pessoa. Disponível em: <http://temasemsaude.com/wpcontent/uploads/2016/08/16232.pdf>. Acesso em: 25 julho 2017.

BARDIN, L. Análise de conteúdo. Trad. Luís Antero Reto e Augusto Pinheiro. Lisboa: Edições 70; 2009.

BRASIL. Ministério da Saúde. Secretaria de Atenção à Saúde. Departamento de Ações Programáticas Estratégicas. Manual de atenção à mulher no climatério/menopausa. Brasília (DF): Ministério da Saúde; 2008. (Série A. Normas e Manuais Técnicos) (Série Direitos Sexuais e Direitos Reprodutivos; Caderno 9).

FONTANELLA, B. J. B.; LUCHESI,B. M.; SAIDEL, M. G. B.; RICAS, J.; TURATO,E. R.; MELO,D.G. Amostragem em pesquisas qualitativas: proposta de procedimentos para constatar saturação teórica.Cad Saúde Pública. 2011 ;27(2):389-394. Disponível em: <http://www.scielo.br/pdf/csp/v27n2/20.pdf>. Acesso em 30 agosto 2017.

FREITAS, E. R.; BARBOSA, A. J. G.; REIS, G. A, RAMADA, R.F.; MOREIRA, L. C.; GOMES, L. B.; VIEIRA, I. D.; TEIXEIRA, J. M. S. Educação em menopausa ou "passagem de idade". Ao serem abordadas sobre a interferência da sexualidade na fase do climatério, percebeu- se claramente sentimentos de constrangimento, timidez e insatisfação. Faz- se necessário desenvolver ações de promoção, prevenção e ou recuperação através da Atenção Primária em Saúde, para que dessa forma as mulheres orientadas possam vivenciar este período de forma natural e tranquila.

saúde para mulheres no climatério: impactos na qualidade de vida. Sociedade Brasileira de Reprodução Humana. Reprodução e Climatério, 2016;31(1):37-43. Disponível em: <http://www.sciencedirect.com/science/article/pii/S141 $320871600008 X>$. Acesso em 14 junho 2017.

MELO, C. R. M.; REIS, E. S. R.; SILVA, L. C. F. P.; SOLA, E. P. S.; CHOFAKIA, C. B. N. Aplicação do Índice Menopausal de kupperman: um estudo transversal com mulheres climatéricas.Espaço para a saúde - Revista de Saúde Publica do Paraná. Londrina. Dez 2016; v. 17, n. 2, p. 41-50. Disponível em:

<http://www.uel.br/revistas/uel/index.php/espacoparas aude/article/view/25679/2>. Acesso em 20 setembro 2017.

MIRANDA, J. S.; FERREIRA, M. L. S. M.; CORRENTE, J. E. Qualidade de vida em mulheres no climatério atendidas na Atenção Primária.

RevBrasEnferm. set-out 2014;67(5):803-9.

Disponível em:

<http://www.scielo.br/pdf/reben/v67n5/0034-7167reben-67-05-0803.pdf> . Acesso em 21 setembro 2017.

PASCOAL, L. A.; BORGES, M. M. M. C. A mulher vivenciando o período do climatério. Revista Enfermagem Integrada - Ipatinga: Unileste. Nov./ Dez. 2013; v. 6 - N. 2. Disponível em: $<$ https://www.unilestemg.br/enfermagemintegrada/arti go/v6_2/04-a-mulher-vivenciando-o-periodo-doclimaterio.pdf $>$. Acesso em 25 outubro 2017.

PIRES, A. P. Amostragem e pesquisa qualitativa: ensaio teórico e metodológico. Petrópolis: Ed. Vozes; 2008.

ROCHA, A. W.; NASCIMENTO, E. G. C.; JUNIOR, J. M. P.; ALCHIER, J. C. As incertezas de mulheres 
em vivenciar a sexualidade no climatério. Revenferm UFPE online., Recife, 8(2):314-22, fev., 2014.

SANTOS, S. M. P.; GONÇALVES, R. L.; AZEVEDO, E. B.; PINHEIRO, A. K. D.; BARBOSA, C. A.; COSTA, K. N. F. A vivência da sexualidade por mulheres no climatério. RevEnferm UFSM. Jan/Mar 2014; 4(1):113-122. Disponível em:

$<$ https://periodicos.ufsm.br/reufsm/article/view/8819/p df $>$. Acesso em 21 outubro 2017.

SCHMALFUSSI, J. M.; SEHNEM, G. D.; RESSEL, L. B.; TEIXEIRA, C. M. D. Percepções e vivências das mulheres acerca do climatério. Revenferm UFPE, Recife, 8(9):3039-46, set., 2014.

SILVA, T.B.; BORGES, M. M. M. C. Sexualidade após a menopausa: situações vivenciadas pela Mulher. Revista Enfermagem Integrada -Ipatinga: Unileste. Nov./Dez. 2012; v.5 -N.2. Disponível em:

\section{Fernanda Cristina Beraldo Rezende}

Enfermeira pelas Faculdades Unidas do Norte de Minas- FUNORTE

\section{Hilária Kênia Santos Lisboa}

Enfermeira pelas Faculdades Unidas do Norte de Minas- FUNORTE

\section{Lyllian Aparecida Vieira Almeida}

Especialista em Trauma e Saúde Coletiva. Docente no curso de graduação em Enfermagem das Faculdades Unidas do Norte de Minas- FUNORTE.

\section{Emerson Ribeiro Lima}

Mestre em Biotecnologia pela Universidade Estadual de Montes Claros - UNIMONTES

\section{Meriele Santos Souza}

Especialista em Saúde da Família pelas Faculdades Unidas do Norte de Minas- FUNORTE

\section{Romana AparecidaAlves Barbosa}

Graduação em Medicina pela Universidade Estadual de Montes Claros - UNIMONTES <https://www.unilestemg.br/enfermagemintegrada/arti go/v5_2/08-sexualidade-apos-menopausa-situacoesvicenciadas-pela-mulher.pdf.>. Acesso em 25 de novembro 2017.

SERPA, M.A.; LIMA, A. A.; GUIMARÃES, A. C. P.; CARRILO, M. R. G. G.; VITAL, W. C.; VELOSO, V. M. Fatores associados à qualidade de vida em mulheres no climatério. Sociedade Brasileira de Reprodução Humana. Reprodução e Climatério. . 2016;31(2):76-81. Disponível em:

<http://www.sciencedirect.com/science/article/pii/S141 3208716300152>. Acesso em 26 de novembro 2017. VALENÇA, C.N.; GERMANO, R.M. Concepções de mulheres sobre menopausa e climatério. Rev. Rene. Fortaleza. jan./mar.2010; v. 11, n. 1, p. 161-171. Disponível em:

<http://www.periodicos.ufc.br/index.php/rene/article/vi ew/4498/3398>. Acesso em 28 de novembro de 2017.

\section{Mariza Alves Barbosa Teles}

Mestre em Ciências da Saúde pela Universidade Estadual de Montes Claros - UNIMONTES. Docente no curso de graduação em Enfermagem das Faculdades Unidas do Norte de Minas- FUNORTE

\section{Karla Chistiane Freitas Oliveira}

Especialista em Prevenção e Controle de Infecção Hospitalar. Docente no curso de graduação em Enfermagem das Faculdades Unidas do Norte de Minas- FUNORTE 